\title{
Study on the Transmission Mechanism of Price of Cattle and Sheep in China
}

\author{
Jie $\mathrm{YU}^{1, \mathrm{a}}$, Xiao HAN²,b , Zhong-Wei HE, ${ }^{\mathrm{c}, *}$, Fang LIU ${ }^{\mathrm{d}, *}$ \\ Economic and Management School, BUA, Beijing, China \\ ayujie6611@163.com, chzw28@126.com \\ ${ }^{*}$ Corresponding author
}

Key words: Cattle and sheep industry, Long-term equilibrium price, Price protection mechanism.

\begin{abstract}
In this paper, the vector auto regression mode (VAR) is used; Johansen test is conducted among independent variables which sheep and cattle industry chain involved. China's price transmission mechanism is analyzed of. Studies have shown that the presence of cattle and sheep industry chain have long-term equilibrium. Prices of Feed and raw materials of feed for cattle and sheep fluctuations play a decisive role. But cattle and sheep prices fluctuating in recent years, in the long run, equilibrium price exists and cattle sheep industry chain have limited ability to repair itself, the government should improve the existing price protection mechanism to protect cattle sheep industry.
\end{abstract}

\section{Introduction}

At present, Chinese cattle and sheep production account respectively third and first in the world, while, beef and mutton price high volatility caused widespread concern in the community. According to data from the Ministry of Agriculture sentinel monitoring rural bazaars livestock and feed prices showed that in January 2007, the national average price of beef and mutton $20 \mathrm{Yuan} / \mathrm{kg}$, that price until June 2013 has risen to 57.05 Yuan $/ \mathrm{kg}$, up nearly three times. Beef and mutton prices rose $84 \%$ and 52\%, respectively, from 2008 to 2012, in 2013 continue to rise. Along with the advance of a well-off society, people's living standards improved the consumption of cattle and sheep is increasing. Folk tradition in some areas, combined with clenbuterol, avian flu and other quality and safety issues followed, drive consumer to consumer beef or mutton, instead of pork and chicken. In addition, cost of farming rising, breeding efficiency declining, output growth slowing down, or even decline; some places are in short supply. In the long run, the gap between supply and demand will continue to increase.

There are some researches on agricultural prices transmission mechanism. Cushing used empirical studies on American price transmission mechanism and found that prices of producer index to the consumer price transmission mechanism is more important than the one that consumer prices to the producer price. Zhang Lixiang and Zhang Xicai studied on agricultural industrial chain price transmission mechanism; found that the price transmission of part of agricultural products is sluggish. Other agricultural products price adjust slowly in the short term, the upstream and downstream products price fluctuations extrusion can conduct price to the upstream and downstream products, vice is not set up. He Zhongwei used VAR model to analyze the effect of price transmission in the pig industry chain to the inflation in China. The conclusion is that there is a relative determined balance between the production and marketing, price transmission smooth. It has a long time that the price in different stages of the industrial chain short-term fluctuations to recover. This paper empirically research on the price volatility of cattle and sheep industry, and grasp price stability and transmission mechanism of cattle and sheep industry. Aims to put forward the effectiveness of macroeconomic regulation and control mechanism, and prevent price volatility in the hog industry to occur in cattle and sheep industry. 


\section{Research methods, variables and date sourses}

\section{Data sources}

According to the characteristics of the development of Chinese cattle and sheep, live cattle and sheep prices, feed raw material prices, feed prices, beef and mutton prices are an important part of the price of Chinese cattle and sheep industrial chain from production processes to consumers. Taking into account the availability and effectiveness of the data, this paper will take corn prices as a representative of the prices of raw material of feed. Because corn is important raw materials in fattening feed for cattle and sheep, which the ratio is up to $60 \%$ in the fine feed. It can better represent upstream product market. In addition, because there is no statistical data on feed prices, this paper selected the feed price index instead of feed prices generally. The price of live cattle and sheep was taken as a representative of the price of intermediate goods of middle reaches in cattle and sheep industry. Due to category of cattle and sheep is various and statistics are difficult, the paper used cattle and sheep's producer price index instead. Beef and mutton boneless price represent the downstream final consumer prices. Those four kinds of prices composed of cattle and sheep industry pricing system and represent the main price of cattle and sheep industry chain. From the perspective of production and supply, this paper has taken cattle and sheep industry price system as the research object, revealed the transmission relationship between the price transmission mechanism in upstream, midstream and downstream of cattle and sheep industry and explored Chinese cattle and sheep industry price fluctuations rule. All relevant data come from China Animal Industry Yearbook, China's agricultural prices yearbook and the website of the Ministry of Agriculture in 2005-2012. Data involved in the model has been processed with logarithm method to avoid the impact of heteroscedasticity of the model.

\section{Research methods}

This paper used the vector autoregressive model to analysis time series. When analyzing the middle price' impacts on cattle and sheep prices, the article conduct research through cointegration test and make impulse response and variance decomposition to analyze influence degree of the industry chain each link to downstream products' price.

This paper mainly involves the vector autoregressive model, which is one of dealing with analysis and prediction of several relevant economic indicators model. VAR (p) model simplified mathematical expression is:

$$
\mathrm{y}_{\mathrm{t}}=\mathrm{A}_{1} \mathrm{y}_{\mathrm{t}-1}+\ldots+\mathrm{A}_{\mathrm{p}} \mathrm{y}_{\mathrm{t}-\mathrm{p}}+\mathrm{BX} \mathrm{X}_{\mathrm{t}}+\varepsilon_{\mathrm{t}}
$$

Among them: $y t$ is endogenous variable, $\mathrm{Xt}$ is an exogenous variable, $\mathrm{p}$ is lag order, $\mathrm{et}$ is random perturbation terms.

\section{Stationary test}

Before analyzing the price transmission mechanism of cattle and sheep industry chain, firstly, examine the variables stationary. This paper choose the ADF test, and the results show that the six variables are I (1) process. Co-integration theory premise is to keep the data stationary, I (1) process to meet the prerequisite for further analysis (as shown in Tables 1 and 2).

Next step is to test whether there is co-integration relationship between four price variables of their respective industry chain, namely whether there is a long-run equilibrium relationship in cattle and sheep industry price system. But, before confirming whether there has co-integration relationship, it is need to confirm lag order of VAR model. 


\section{Determination of lag}

Determination of lag is the necessary premise for establish VAR model. This paper using the method of comprehensive criteria, namely, in LR, FPE, HQ, SC and AIC standards, model lag order number has the most optimal lag. Most of them choose lag phase 2 in table 2, so that VAR model selected lag 2. Its need to test the overall stability of the model before using VAR model. This paper introduced the unit circle in order to more intuitive

Table 1 cattle and sheep industry chain price variable stationary test results

\begin{tabular}{ccccc}
\hline & ADF statistic & P value & Inspection form & conclusion \\
\hline LnX1 & 4.598622 & 1.0000 & $(\mathrm{c}, 0,0)$ & non-stationary \\
LnX2 & 4.771548 & 1.0000 & $(\mathrm{c}, 0,0)$ & non-stationary \\
LnX3 & 2.775683 & 0.9985 & $(\mathrm{c}, 0,0)$ & non-stationary \\
LnX4 & -0.026221 & 0.6712 & $(\mathrm{c}, 0,0)$ & non-stationary \\
LnX5 & -0.049385 & 0.6635 & $(\mathrm{c}, 0,0)$ & non-stationary \\
LnX6 & -0.139784 & 0.6325 & $(\mathrm{c}, 0,0)$ & non-stationary \\
D(LnX1) & -4.921354 & 0.0000 & $(\mathrm{c}, 0,0)$ & stationary \\
D(LnX2) & -6.073415 & 0.0000 & $(\mathrm{c}, 0,0)$ & stationary \\
D(LnX3) & -4.965622 & 0.0000 & $(\mathrm{c}, 0,0)$ & stationary \\
D(LnX4) & -12.22084 & 0.0000 & $(\mathrm{c}, 0,0)$ & stationary \\
D(LnX5) & -11.6041 & 0.0000 & $(\mathrm{c}, 0,0)$ & stationary \\
D(LnX6) & -10.67681 & 0.0000 & $(\mathrm{c}, 0,0)$ & stationary \\
\hline
\end{tabular}

Note: X1, X2, X3, X4, X5, X6 distribution represents beef price, mutton prices, corn prices, feed price index, beef producer price index, mutton producer price index.

Table 2 determine the lag order of number of cattle industry chain

\begin{tabular}{ccccccc}
\hline Lag & LogL & LR & FPE & AIC & SC & HQ \\
\hline 0 & 584.8649 & NA & $6.94 \mathrm{e}-12$ & -14.34234 & -14.22410 & -14.29490 \\
1 & 1076.382 & 922.3529 & $5.53 \mathrm{e}-17$ & -26.08350 & $-25.49228^{*}$ & -25.84630 \\
2 & 1104.040 & $49.17049^{*}$ & $4.16 \mathrm{e}-17 *$ & $-26.37137 *$ & -25.30717 & $-25.94439^{*}$ \\
3 & 1118.487 & 24.25612 & $4.35 \mathrm{e}-17$ & -26.33301 & -24.79583 & -25.71628 \\
\hline
\end{tabular}

understanding. Test results show that the VAR model overall has stability.

\section{Johansen co-integration test}

Before analyzing the relationship between the market price of cattle and sheep, Firstly, we should determine whether there is a co-integration relationship between each price series. This study uses Johansen co-integration test method based on

VAR model. Unconstrained VAR model is imposed co-integration vectors and constitute co-integration test. So the lag of co-integration test is the optimal lag order of unconstrained VAR model reduction 1. Therefore, the lag order of co-integration test is 1. Observing data characteristics, when tested using the data in linear trend, there is intercept in co-integration equation. Track testing proved that there have co-integration relationships between four sequences. The long-run equilibrium relationship already exists in Chinese cattle and sheep industry chain. Market prices have been stable co-integration change (such as table 4,5 ).

There is a long-term equilibrium relationship in price system of cattle industry chain in the sample period.

$$
\operatorname{Ln}(X 1)=0.9626 \operatorname{Ln}(X 3)+14.9036 \operatorname{Ln}(X 4)-197.6538 \operatorname{Ln}(X 5)
$$


Long-term equilibrium relationship of the price system of sheep industry chain system with the following equation:

$$
\operatorname{Ln}(X 2)=3.1111 \operatorname{Ln}(X 3)+16.2926 \operatorname{Ln}(X 4)+316.7243 \operatorname{Ln}(X 6)
$$

The co-integration equation above can well explain the existence of long-term equilibrium in cattle and sheep industry chain for a long time. But there is a big difference between these two equations in production process. In cattle and sheep industry chain, though the cattle industry and the sheep industry have the same direction on response to corn price, the reaction degree is different. When corn prices rose $1 \%$, beef prices growth rate is increased by $0.96 \%$ and mutton price's is $3.1111 \%$. Cattle and sheep industry are more apparent difference in production processes. Sheep price and sheep production price present negative correlation, while cattle price is negatively correlated with the price of cattle production. Due to the increasing cost of the cattle industry and lack of consumer demand, price of cattle is difficult to increase in the short term. Then farmers give up breeding cattle, saling their supply of goods in great quantities, turning to other varieties. So, cattle oversupply, eventually causing prices to decline significantly. While, sheep consumption group is relatively fixed, mostly Muslim and other ethnic minorities' consumption, demand elasticity of the sheep is smaller than the cattle's. The increase of production cost in the short term will not bring demand fluctuations, thus, causing long-term shortage situation, eventually causing prices to rise.

\section{Study on short-term price conduction}

Examine the short-term price conduction of cattle and sheep industry chain; we need to adopt the method of variance decomposition.

Table 3 determine the lag order of number of sheep industry chain

\begin{tabular}{ccccccc}
\hline Lag & LogL & LR & FPE & AIC & SC & HQ \\
\hline 0 & 597.4417 & NA & $5.09 \mathrm{e}-12$ & -14.65288 & -14.53464 & -14.60544 \\
1 & 1013.223 & 780.2322 & $2.63 \mathrm{e}-16$ & -24.52403 & $-23.93281^{*}$ & -24.28683 \\
2 & 1046.474 & $59.1130^{*}$ & $1.72 \mathrm{e}-16^{*}$ & $-24.94999^{*}$ & -23.88579 & $-24.52301^{*}$ \\
3 & 1059.016 & 21.05793 & $1.89 \mathrm{e}-16$ & -24.86460 & -23.32742 & -24.24786 \\
\hline
\end{tabular}

Table 4 cattle industry chain track test

\begin{tabular}{ccccc}
\hline $\begin{array}{c}\text { Hypothesized } \\
\text { No. of CE(s) }\end{array}$ & Eigenvalue & $\begin{array}{c}\text { Trace } \\
\text { Statistic }\end{array}$ & $\begin{array}{c}0.05 \\
\text { Critical Value }\end{array}$ & Prob.** \\
\hline None $*$ & 0.658405 & 131.7046 & 47.85613 & 0.0000 \\
At most 1 $*$ & 0.380277 & 43.62606 & 29.79707 & 0.0007 \\
At most 2 & 0.048381 & 4.390439 & 15.49471 & 0.8696 \\
At most 3 & 0.003944 & 0.324019 & 3.841466 & 0.5692 \\
\hline
\end{tabular}

Table 5 sheep industry chain track test

\begin{tabular}{|c|c|c|c|c|}
\hline $\begin{array}{l}\text { Hypothesized } \\
\text { No. of CE(s) }\end{array}$ & Eigenvalue & $\begin{array}{c}\text { Trace } \\
\text { Statistic }\end{array}$ & $\begin{array}{c}0.05 \\
\text { Critical Value }\end{array}$ & Prob.** \\
\hline None $*$ & 0.682069 & 132.1283 & 47.85613 & 0.0000 \\
\hline At most $1 *$ & 0.308501 & 38.16273 & 29.79707 & 0.0043 \\
\hline At most 2 & 0.091690 & 7.913463 & 15.49471 & 0.4747 \\
\hline At most 3 & 0.000336 & 0.027524 & 3.841466 & 0.8682 \\
\hline
\end{tabular}




\section{Impulse response function}

Impulse response function describes the effects of each endogenous variable changes impact itself and other endogenous variable. Cattle and sheep industry chain specific reflection degree is as follows: beef price and mutton price are subject to its current price shock response very quickly, and its effects are far-reaching. Impact of corn price to beef price and mutton price is not obvious, even negative impact is appeared in 1 to 3 cycles. Then the cattle turn into a positive impact after the fourth cycle, and lasting this effect. The influence of feed price to beef price and mutton price is relatively single. It always shows a positive impact from the first cycle and maintains at around $0.5 \%$, with a long duration, strong reaction characteristics. The production processes impact of cattle and sheep industry chain to beef price and mutton price is small. Before the second cycle, the production processes of beef and mutton price has a slight positive impact, and then the effect is weakening rapidly. It's shows that the influence of production processing cost of beef and mutton is almost negligible to beef and mutton prices.

Corn price has the strongest reaction when it hit by itself. It appears positive fluctuations in current period at once, and shock effect is increased, then sustainable in long term. In the short term, the influence of corn price to feed price is positive, and the effect has expand trend for a long time. This is because feed price is closely related to corn price and reciprocal causation each other, so the influence of corn price to feed price is more far-reaching. Corn price presents negative change affected by beef price in first 15 periods. This is because the farmers expect the possibility that feed price rising leads to costs rise and benefits reduce, they reduce the amount in the short term as far as possible. In the current conditions of higher returns, farmers sell more cattle and reduce future possible losses. After the adjustment of price and amount in 15 cycles, the corn price will effectively transmit to cattle prices.

Feed price is related to the whole industry chain. If feed price is not stable, it will cause sharp fluctuations in the industrial chain. The impact of feed price and production price to the whole industry chain is the process of short-term volatility and long-term convergence. The cattle and sheep industry affected by the feed price and production process complicatedly and violently in the first 15 cycle. This is because these links are very close to the consumer market, and with the conduction time is short, short-term effects are big uncertainty and other characteristics. Therefore, feed link and security and stability of production is an important factor to ensure cattle and sheep price steady in the short-term steady.

\section{Variance analysis}

After analyzing the conduction of each endogenous variables in cattle and sheep chain, it's need to know the contribution degree of the impact to variables in the model. Variance decomposition is used here for analysis. In the variance analysis table of cattle price, it is observed which index has the largest contribution degree. This paper mainly discusses the influence of each link in the industrial chain to cattle and sheep consumer prices, so, only intercept variance analysis of each link price to cattle and sheep price. (Table 6,7)

Cattle price changes completely from itself when forecast cattle price in the first period. In the contributions ingredients that change cattle price in the fifth period, feed price fluctuation accounted for $22.65 \%$, corn price fluctuation accounted for $3.23 \%$, cattle production price fluctuation accounted for $0.22 \%$. When predicting period is extended to 30 period, there is include only $17.65 \%$ beef price changes, $50.94 \%$ corn price, $31.07 \%$ feed prices, $0.34 \%$ beef production price.

In the first forecast period, the change of sheep price has $82.71 \%$ from itself, only $4.00 \%$ from corn price, $9.47 \%$ from feed price, and $3.82 \%$ from sheep production price. When the forecast period extended to 30 , mutton price change because of itself is $18.67 \%$, corn price climbs to $66.75 \%$, feed price remains at $14.17 \%$, and mutton production price is only $0.41 \%$. 


\section{Main conclusions}

Through the study above price conduction mechanism of cattle and sheep industry chain can fully understand the impact mechanism of industry chain consumer price. There is a long-term co-integration relationship in cattle and sheep industry chain in China, vertical market integration degree is high. From the above study the following three conclusions can be drawn:

Firstly, in the long run, it appears a positive change between cattle and sheep price with corn and feed price. It indicates that feed production is the key to constrain and influence the development of cattle and sheep industry. In order to maintain the price of cattle and sheep stability, it's need to strengthen the management of feed raw materials and feed processing link docking. Short-term adjustment mechanism showes that cattle and sheep industry is an industry with rising production cost. The impact of feed raw materials price is the most far-reaching to the price of cattle and sheep. In the short term, it has the biggest influence on volatile prices of cattle and sheep.

Secondly, the short-term adjustment speed of beef production price is faster than mutton price's, so that it maintains equilibrium relationship in the long term. It shows that producers affected more largely in the cattle industry. Producers can add beef production when cattle price is high to balance supply-demand relationship of beef. Mutton consumption group is relatively fixed. The short-term industry volatility had a greater influence on long-term equilibrium adjustment. So, it is difficult to return to equilibrium. That is to say back to long-term equilibrium at a slower speed.

Thirdly, impulse response and variance analysis showed that feed price affected by cattle and beef price, as well as its raw material price. And it aggravate volatility of beef price and mutton price. Feed price and corn price are mainly influenced by comprehensive influence of supply and demand of corn at home and abroad, and adjust the price of cattle and sheep relatively slowly. In the long term, corn price has the largest contribution to the beef and sheep price fluctuations. Therefore, from the aspect of industry security, guaranteeing the price of cattle and sheep is accent on getting rid of the influence of foreign corn. Generally speaking, through controlling purchase price and cost, improve the overall efficiency of cattle and sheep industry. It can forecast feed raw material price trend, increase supply capacity, and improve cattle and sheep industry benefits.

\section{Acknowledgements}

Thanks to my mentor Professor He Zhongwei and Liu Fang careful guidance of this article. From the perspective of writing methods, to complete the paper, Professors devoted mounts of efforts and sweat. Also, thanks to the support of this thesis Fund: 2013 Department of Agriculture soft science topics (201309); 2013 National Natural Science Foundation of China (71373025); Colleges and Universities in Beijing Talent introduction and Training projects (CIT\& TCD20140314); Beijing Agricultural College Advantaged Technology team (Beijing agricultural industry security theory and policy research innovation team) projects. This paper's corresponding authors are He Zhongwei and Liu Fang.

\section{References}

[1] Cushing,Matthew J,Mary Get al. Feedback between wholesale and consumer price inflation: A re-examination of the evidence. Southern Economic Journal, 1990(56): 1059-1072.

[2] Zhang Xicai Zhang Lixiang. Research on mechanism of the transmission and regulation of price fluctuation in the agricultural industry chain. Economic theory and management theory, 2011(1):104-112.

[3] He Zhongwei, Wang Chen, Liu Fang. Research on the price conduction and regulatory mechanism between production and marketing in the pig industrial. Journal of Agro technical Economics, 2012(8):38-45. 